Research Article

\title{
Internal Force Analysis and Field Test of Lattice Beam Based on Winkler Theory for Elastic Foundation Beam
}

\author{
Jingbang Li $\mathbb{D}^{1,2}$ Yanpeng Zhu, ${ }^{1,2}$ Shuaihua Ye $\mathbb{D}^{1,2}$ and Xiaorui $\mathrm{Ma}^{1,2}$ \\ ${ }^{1}$ Key Laboratory of Disaster Prevention and Mitigation in Civil Engineering of Gansu Province, \\ Lanzhou University of Technology, Lanzhou 730050, China \\ ${ }^{2}$ Western Engineering Research Center of Disaster Mitigation in Civil Engineering, Ministry of Education, \\ Lanzhou University of Technology, Lanzhou 730050, China \\ Correspondence should be addressed to Jingbang Li; lst_123143567@163.com
}

Received 4 July 2019; Revised 2 October 2019; Accepted 15 October 2019; Published 18 November 2019

Academic Editor: Francesco Marotti de Sciarra

Copyright (c) 2019 Jingbang Li et al. This is an open access article distributed under the Creative Commons Attribution License, which permits unrestricted use, distribution, and reproduction in any medium, provided the original work is properly cited.

\begin{abstract}
As a new flexible supporting structure, prestressed anchor cable lattice beams have been widely used in high-slope support engineering and have achieved good results. However, theoretical research on the internal force analysis of lattice beams is far behind engineering practice. Based on the theory of the Winkler elastic foundation model, a mechanical model of a prestressed anchor cable lattice beam at the tension stage was established. Considering the nonhomogeneous lattice beam materials, a calculation method was given and applied to engineering examples. A calculation method of the measured moment was introduced in the field test conducted in the Zhouqu County " $8 \cdot 8$ " debris flow disaster reconstruction project. Comparisons between the test results and the theoretical results were performed. The results showed that the theoretical results of the distribution trend of the lattice beam moment were consistent with the test results, which verified the rationality of the proposed calculation method. The inertia moment of the beam section solved by the transformed section method was more realistic. The results of the transformed section method could improve the bending resistance of the lattice beam and reduce the reinforcement ratio. The greater the anchoring force was, the more obvious the lifting effect was. The anchoring force was an important influencing factor of the internal force of the lattice beam. The greater the anchoring force was, the greater the lattice beam moment was, and they showed the same proportional change phenomenon. Compared with the theoretical moment, the measured moment obtained by the test was smaller, which indicated that the lattice beam of the tested slope was safe at the present stage.
\end{abstract}

\section{Introduction}

In recent years, with population increases [1], global climate changes $[2,3]$, and the expansion of human activity [4], landslides occur frequently and cause significant loss of life and property worldwide every year $[5,6]$. China possesses many mountainous areas, and the safety of people's lives and property is seriously threatened by landslides and slope instability $[7,8]$. Therefore, a large number of experts and scholars are engaged in the study of slope reinforcement technology, and a variety of support forms have emerged successively, such as retaining walls [9], soil-nail retaining structures [10], antislide piles [11], anchors [12], and anchor cable lattice beams [13].
As a new flexible supporting structure, a prestressed anchor cable lattice beam has been widely used in high-slope support engineering [14]. In the past, empirical analogy methods and inverted beam methods have mostly been used to calculate the internal force of lattice beams [15-17]. These two methods ignore the interaction between the lattice beam and the rock and soil mass, which causes the calculation results to be inconsistent with those under the actual force. As a result, the slope becomes unsafe. In recent years, with the application of the calculation method based on elastic foundation beam theory, the Winkler elastic foundation model, the two-parameter elastic foundation model, the elastic half-space foundation model, and other theoretical models have emerged [18]. Only considering the load 
transfer effect by the longitudinal beam, Xu and Tang [19] selected the Winkler elastic foundation model to analyze the internal force and deformation of lattice beams. Regarding the lattice beam as a beam acting on the two-parameter elastic foundation, Zhou [20] deduced the initial parameter method of the two-parameter foundation beam to solve its internal force. Song et al. [21] calculated the internal force of the lattice beam based on the elastic half-space foundation model and suggested that the internal force of the lattice beam should be calculated according to the tension stage and the working stage. How to choose the appropriate foundation model becomes the key to solving the practical problem. Either the two-parameter elastic foundation model or the elastic half-space foundation model can consider the dispersion of stress and displacement in the foundation. However, these two methods have obvious defects, such as the complexity of the calculation process, the difficulty of the solution, the difficulty of selecting the key parameters, and the lack of relevant test verification. Although the results are conservative, the Winkler elastic foundation model is simple to calculate, and the results can meet the requirements of engineering practice, which is verified by tests $[19,22]$. Therefore, the Winkler elastic foundation model facilitates engineering applications.

Based on the Zhouqu County " 8.8 " debris flow disaster reconstruction project, combined with the theoretical calculation with the field test, the distribution regularity of the lattice beam internal force in the tension stage is studied in this paper. Selecting the Winkler elastic foundation model to analyze the internal force of the lattice beam, a calculation method for the internal force of the lattice beam in the tension stage is given. Compared with the field test, the theoretical calculation results are verified. This paper considers the interaction between the lattice beam and the rock and soil mass and reflects the actual force status of the lattice beam. It can provide a reference for the design and test of the prestressed anchor cable lattice beam in a similar high slope.

\section{Internal Force Analysis of the Lattice Beam Based on the Winkler Elastic Foundation Model}

In the design of a lattice beam, the foundation soil is idealized as a linear elastomer in the calculation method based on the Winkler elastic foundation model. It is assumed that the settlement at any point on the ground surface is proportional to the pressure on the unit area at that point. Regarded as a beam acting on the foundation, the lattice beam on the slope is subject to a number of anchoring forces and subgrade reactions.

2.1. Basic Theory of the Winkler Elastic Foundation Model. According to the Winkler assumption, the relationship between the pressure intensity at any point on the surface of the foundation soil and the settlement of the foundation soil at that point can be expressed as follows [18]:

$$
p(x)=k s,
$$

where $p(x)$ is the subgrade reaction in $\mathrm{kPa}, s$ is the settlement of the foundation soil, and $k$ is the coefficient of subgrade reaction in $\mathrm{kN} / \mathrm{m}^{3}$, which can be determined by the characteristics of the rock and soil mass or field tests.

According to the mechanics of materials, the deflection differential equation of the beam on the elastic foundation can be derived as follows:

$$
E I \frac{\mathrm{d}^{4} \omega}{\mathrm{d} x^{4}}+b p(x)=q(x),
$$

where $E$ (in $\mathrm{kPa}$ ), $I\left(\right.$ in $\left.\mathrm{m}^{4}\right), \omega$, and $b$ are the elastic modulus, sectional inertia moment, deformation, and width of the beam, respectively, and $q(x)$ is the load on the beam in $\mathrm{kPa}$.

According to the deformation compatibility condition, $s$ is equal to $\omega$. Substituting $p(x)$ from equation (1) in equation (2), a new equation can be deduced as follows:

$$
E I \frac{\mathrm{d}^{4} \omega}{\mathrm{d} x^{4}}+k b \omega=q(x) .
$$

Equation (3) is a fourth-order linear nonhomogeneous differential equation with constant coefficients. If $q(x)$ is a polynomial below third-order, a special solution $\omega_{1}(x)$ of equation (3) for deformation is as follows:

$$
\omega_{1}(x)=\frac{q(x)}{k} .
$$

At $q(x)=0$, the homogeneous equation corresponding to equation (3) can be obtained as follows:

$$
E I \frac{\mathrm{d}^{4} \omega}{\mathrm{d} x^{4}}+k b \omega=0
$$

The general solution of equation (5) for deformation $\omega$ is as follows:

$$
\omega=e^{\lambda x}\left(C_{1} \cos \lambda x+C_{2} \sin \lambda x\right)+e^{-\lambda x}\left(C_{3} \cos \lambda x+C_{4} \sin \lambda x\right),
$$

where $\lambda$ (in $\mathrm{m}^{-1}$ ) is the flexibility eigenvalue of the beam, and $\lambda=\sqrt[4]{\mathrm{kb} / 4 E I}, C_{1}, C_{2}, C_{3}$, and $C_{4}$ are unsolved integral constants that can be obtained by the load and boundary conditions.

Thus, the general solution of inhomogeneous equation (3) for deformation $\omega$ is as follows:

$$
\begin{aligned}
\omega= & e^{\lambda x}\left(C_{1} \cos \lambda x+C_{2} \sin \lambda x\right)+e^{-\lambda x}\left(C_{3} \cos \lambda x+C_{4} \sin \lambda x\right) \\
& +\omega_{1}(x) .
\end{aligned}
$$

2.2. Internal Force Analysis of the Infinite-Length Beam. The relative stiffness of the beam and foundation has an important influence on the force status of the beam. It is assumed that the beam is infinitely long at first, and the beam under the vertical concentrated force $P_{0}$ is shown in Figure 1 (positive as shown). 


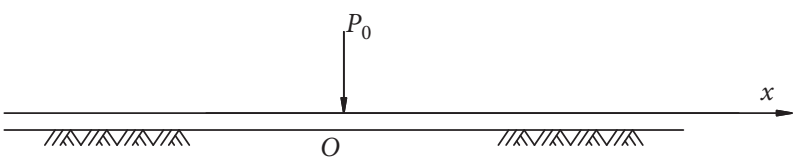

Figure 1: The infinite beam under concentrated force.

Taking the action point of concentrated force $P_{0}$ as origin of coordinates $O$, the boundary conditions are as follows:

$$
\left.\begin{array}{l}
x \longrightarrow+\infty, \bar{\omega} \longrightarrow 0, \\
x=0, \quad \frac{\mathrm{d} \bar{\omega}}{\mathrm{d} x}=0,
\end{array}\right\}
$$

where $\bar{\omega}$ is deformation of the infinite-length beam.

At $x=0$ on the right section of origin $O$, the shear force $\bar{V}$ of the section is as follows:

$$
\bar{V}=-\frac{P_{0}}{2},
$$

where $\bar{V}$ is the shear force of the infinite-length beam section.

Since there is no load on the right of $O$, according to Section 2.1 of this paper, the special solution of the infinitelength beam for deformation is zero. According to the mechanics of materials, joining equations (7)-(9), the deformation, moment, and shear force of the beam on the right of $O(x \geq 0)$ can be obtained as follows:

$$
\left.\begin{array}{l}
\bar{\omega}_{P_{0}}^{+}=\frac{P_{0} \lambda}{2 k b} e^{-\lambda x}(\cos \lambda x+\sin \lambda x), \\
\bar{M}_{P_{0}}^{+}=\frac{P_{0}}{4 \lambda} e^{-\lambda x}(\cos \lambda x-\sin \lambda x), \\
\bar{V}_{P_{0}}^{+}=-\frac{P_{0}}{2} e^{-\lambda x} \cos \lambda x,
\end{array}\right\}
$$

where $\bar{\omega}_{P_{0}}^{+}, \bar{M}_{P_{0}}^{+}$, and $\bar{V}_{P_{0}}^{+}$are the deformation, moment, and shear force of the beam, respectively, on the right of $O$ under the concentrated force $P_{0}$.

Similarly, the deformation, moment, and shear force of the beam on the left of $O(x<0)$ can be obtained as follows:

$$
\left.\begin{array}{l}
\bar{\omega}_{P_{0}}^{-}=\frac{P_{0} \lambda}{2 k b} e^{-\lambda x}(\cos \lambda x+\sin \lambda x), \\
\bar{M}_{P_{0}}^{-}=\frac{P_{0}}{4 \lambda} e^{-\lambda x}(\cos \lambda x-\sin \lambda x), \\
\bar{V}_{P_{0}}^{-}=\frac{P_{0}}{2} e^{-\lambda x} \cos \lambda x,
\end{array}\right\}
$$

where $\bar{\omega}_{P_{0}}^{-}, M_{P_{0}}^{-}$, and $\bar{V}_{P_{0}}^{-}$are the deformation, moment, and shear force of the beam, respectively, on the left of $O$ under the concentrated force $P_{0}$.

Changing the vertical concentrated force $P_{0}$ to the concentrated couple $M_{0}$ with clockwise, the deformation, moment, and shear force of the beam on both sides of origin can be obtained in a similar way:

At $x \geq 0$ :

$$
\left.\begin{array}{l}
\bar{\omega}_{M_{0}}^{+}=\frac{M_{0} \lambda^{2}}{k b} e^{-\lambda x} \sin \lambda x, \\
\bar{M}_{M_{0}}^{+}=\frac{M_{0}}{2} e^{-\lambda x} \cos \lambda x, \\
\bar{V}_{M_{0}}^{+}=-\frac{M_{0} \lambda}{2} e^{-\lambda x}(\cos \lambda x+\sin \lambda x),
\end{array}\right\}
$$

where $\bar{\omega}_{M_{0}}^{+}, \bar{M}_{M_{0}}^{+}$, and $\bar{V}_{M_{0}}^{+}$are the deformation, moment, and shear force of the beam, respectively, on the right of $O$ under the concentrated couple $M_{0}$.

At $x<0$ :

$$
\left.\begin{array}{l}
\bar{\omega}_{M_{0}}^{-}=-\frac{M_{0} \lambda^{2}}{k b} e^{-\lambda x} \sin \lambda x, \\
\bar{M}_{M_{0}}^{-}=-\frac{M_{0}}{2} e^{-\lambda x} \cos \lambda x, \\
\bar{V}_{M_{0}}^{-}=-\frac{M_{0} \lambda}{2} e^{-\lambda x}(\cos \lambda x+\sin \lambda x),
\end{array}\right\}
$$

where $\bar{\omega}_{M_{0}}^{-}, \bar{M}_{M_{0}}^{-}$, and $\bar{V}_{M_{0}}^{-}$are the deformation, moment, and shear force of the beam, respectively, on the left of $O$ under the concentrated couple $M_{0}$.

2.3. Internal Force Analysis of the Finite-Length Beam. To simplify the calculation, the lattice beam is usually divided into several cross beams and vertical beams in practical engineering of slope reinforcement, and each beam is a finite-length beam. The anchoring force of the anchor cable can be simplified to a concentrated force acting on the beam, and a beam is usually subjected to multiple anchoring forces. Therefore, the superposition method [22] can be used to solve the internal force of the lattice beam.

To offset the shear force $F_{a}, F_{b}$ and moment $M_{a}, M_{b}$ under the load on both ends of the beam, it is assumed at first that there are two pairs of boundary condition forces $F_{A}, M_{A}$ and $F_{B}, M_{B}$ on the outside of both end sections of the beam, and then, the internal force can be solved by equations (10) to (13). The finite-length beam under multiple concentrated forces is shown in Figure 2 (positive as shown).

Joining equations (10)-(13), the following can be obtained as follows: 


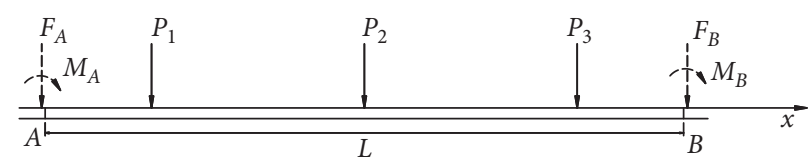

FIGURE 2: Finite-length beam under multiple concentrated forces.

$$
\left.\begin{array}{l}
\frac{F_{A}}{4 \lambda}+\frac{F_{B}}{4 \lambda} e^{-\lambda L}(\cos \lambda L-\sin \lambda L)+\frac{M_{A}}{2}-\frac{M_{B}}{2} e^{-\lambda L} \cos \lambda L=-M_{a}, \\
-\frac{F_{A}}{2}+\frac{F_{B}}{2} e^{-\lambda L} \cos \lambda L-\frac{M_{A} \lambda}{2}-\frac{M_{B} \lambda}{2} e^{-\lambda L}(\cos \lambda L+\sin \lambda L)=-V_{a}, \\
\frac{F_{A}}{4 \lambda} e^{-\lambda L}(\cos \lambda L-\sin \lambda L)+\frac{F_{B}}{4 \lambda}+\frac{M_{A}}{2} e^{-\lambda L} \cos \lambda L-\frac{M_{B}}{2}=-M_{b}, \\
-\frac{F_{A}}{2} e^{-\lambda L} \cos \lambda L+\frac{F_{B}}{2}-\frac{M_{A} \lambda}{2} e^{-\lambda L}(\cos \lambda L+\sin \lambda L)-\frac{M_{B} \lambda}{2}=-V_{b},
\end{array}\right\}
$$

where $L$ is the length of the beam and $M_{a}, M_{b}, V_{a}$, and $V_{b}$ are the moments and the shear forces on both end sections of the beam, which are calculated by the superposition method under the known load.
In practical engineering, the loads acting on the lattice beam are generally symmetrically distributed. Therefore, $V_{a}=-V_{b}, M_{a}=M_{b}$, and the solutions of equation (14) are as follows:

$$
\left.\begin{array}{l}
F_{A}=F_{B}=\frac{2 e^{\lambda L}}{\operatorname{sh} \lambda L+\sin \lambda L}\left\{\left(1+e^{-\lambda L} \cos \lambda L\right) V_{a}+\lambda\left[1-e^{-\lambda L}(\cos \lambda L+\sin \lambda L)\right] M_{a}\right\}, \\
M_{A}=-M_{B}=-\frac{2 e \lambda L}{\operatorname{sh} \lambda L+\sin \lambda L}\left\{\left[1+e^{-\lambda L}(\cos \lambda L-\sin \lambda L)\right] \frac{V_{a}}{2 \lambda}+\left(1-e^{-\lambda L} \cos \lambda L\right) M_{a}\right\} \cdot
\end{array}\right\}
$$

In the end, under the action of the boundary condition forces and the loads on the beam, the deformation, moment, and shear force at any section of the finite-length beam can be solved by the superposition method.

2.4. Analysis of the Moment of Inertia on the Lattice Beam Section. When the Winkler elastic foundation model is used to calculate the internal force of the lattice beam, the flexibility eigenvalue $\lambda$ is an important index to measure the flexural rigidity of the lattice beam. The smaller the value of $\lambda$ is, the greater the flexural rigidity of the beam; that is, the resistance to the bending deformation of the beam is stronger. According to equation (6), while the material and size of the lattice beam are determined, and the coefficient of subgrade reaction $k$ is known, the inertia moment $I$ is the only influence factor of $\lambda$.

When determining the inertia moment of the rectangular section, the lattice beam is often regarded as a single material, and then, the inertia moment [23] can be solved as follows:

$$
I=\frac{b h^{3}}{12}
$$

where $h$ is the height of the beam.

In practical engineering, the lattice beam is a composite material composed of steel and concrete. When calculating the internal forces, it is necessary to consider the nonhomogeneous nature of the material. Therefore, the composite material composed of steel and concrete is converted into a single material by the transformed section method [24] in this paper, namely, the steel area in tensile zone $A_{\mathrm{s}}$ and the steel area in compression zone $A_{\mathrm{s}}^{\prime}$ are transformed into the imaginary concrete area $n A_{s}$ and $n A_{s}^{\prime}$, respectively, at the design position of the section $n=E_{\mathrm{s}} / E_{\mathrm{c}}$, where $E_{\mathrm{s}}$ is the elastic modulus of the reinforcement and $E_{\mathrm{c}}$ is the elastic modulus of the concrete. According to material mechanics, the inertia moment $I_{c}$ of the transformed section to the neutral axis can be obtained as follows:

$$
I_{\mathrm{c}}=\frac{b}{3}\left[x_{0}^{3}+\left(h-x_{0}\right)^{3}\right]+n A_{\mathrm{s}}\left(h_{0}-x_{0}\right)^{2}+n A_{0}^{\prime}\left(x_{0}-a^{\prime}\right)^{2},
$$

where $h_{0}$ is the effective height of the beam section, $a^{\prime}$ is the cover thickness of the steel in the compression zone, and $x_{0}$ is the neutral axis height of the transformed section, which 
can be solved by the following equation (18) according to material mechanics:

$$
x_{0}=\frac{(1 / 2) b h^{2}+n A_{s} h_{0}+n A_{s}^{\prime} a^{\prime}}{b h+n A_{\mathrm{s}}+n A_{\mathrm{s}}^{\prime}} .
$$

\section{Engineering Example}

3.1. Project Overview. The Chunchang Road high slope is located on the east side of Chunchang South Road in Zhouqu County, Gansu Province. The toe of the slope is adjacent to a city road, and on the other side of the road is a residential area, as shown in Figure 3. Historically, the slope has collapsed many times in varying degrees, which has posed a great threat to the lives and property of the local people. The slope reinforcement project belongs to the Zhouqu " $8 \cdot 8$ " heavy debris flow disaster reconstruction project. The safety grade of the reinforcement design is class one. The soil layer distribution on the slope is shown in Table 1.

According to the field reconnaissance results and the measured topographic map, the length of the slope needing strengthening is approximately $344.5 \mathrm{~m}$. The protective height is $9.0-48.5 \mathrm{~m}$, and the slope angle is $45^{\circ}-70^{\circ}$. The strengthened area number is ABCDEFGH. The segment AB of the slope is taken as the research object in this paper, and the slope before reinforcement is shown in Figure 4 . The protective height of segment $A B$ is $48.5 \mathrm{~m}$, and the design angle is $41.3^{\circ}$. The typical section of the segment $A B$ reinforcement design is shown in Figure 5. The $3 \mathrm{~m}$ high slurry masonry retaining wall is built at the slope toe, and the upper slope above the retaining wall is strengthened by a prestressed anchor cable lattice beam. Each lattice beam consists of three cross beams (named $\mathrm{H}_{1}, \mathrm{H}_{2}$, and $\mathrm{H}_{3}$ from downslope to upslope) and three vertical beams (named $S_{1}, S_{2}$, and $S_{3}$ from left to right), and the lattice beam section is rectangular, $0.3 \mathrm{~m}$ long and $0.3 \mathrm{~m}$ wide. The plane dimension of the lattice beam is shown in Figure 6. The angle between the anchor cable and the horizontal plane is $45^{\circ}$, and the anchoring force is $230 \mathrm{kN}$.

\subsection{Analysis Conditions for the Internal Force of the Lattice} Beam. The internal force analysis of the prestressed anchor lattice beam should be carried out in the tension stage and the working stage [25], and the tension stage is the moment when the anchor cable tensioning has just been completed. In the calculation, the lattice beam is divided into cross beams and vertical beams, and the interaction between the lattice beam and the rock and soil mass of the slope is considered. Therefore, the force and deformation of the lattice beam node must satisfy the static equilibrium condition and the deformation compatibility condition.

The static equilibrium condition can be expressed as follows:

$$
P_{i} \cos \left(90^{\circ}-\alpha-\theta\right)=P_{i x}+P_{i y},
$$

where $P_{i}$ (in $\mathrm{kN}$ ) is the total anchoring force of the anchor cable at the lattice beam node $i, \alpha$, and $\theta$ are the angle of the

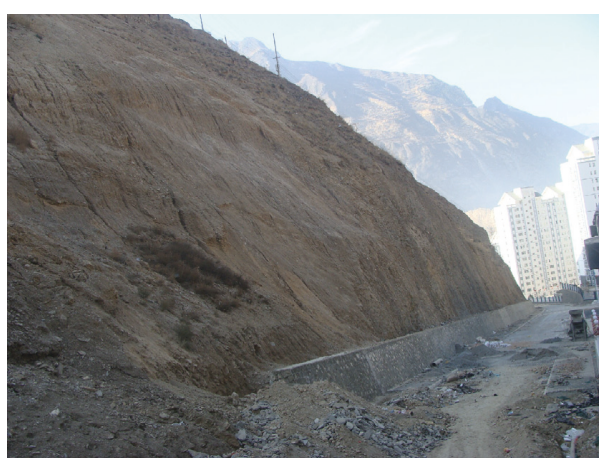

FIgURE 3: Slope field.

slope toe and the dip of the anchor cable, respectively; $P_{i x}$ and $P_{i y}$ are the component forces distributed in the cross beam and the vertical beam, respectively.

The deformation compatibility condition can be expressed as follows:

$$
\omega_{i}=\omega_{i x}=\omega_{i y}
$$

where $\omega_{i}$ is the lattice beam deformation perpendicular to the slope at node $i, \omega_{i x}$, and $\omega_{i y}$ are the cross beam deformation and the vertical beam deformation perpendicular to slope at node $i$ caused by $P_{i x}$ and $P_{i y}$, respectively.

This paper mainly analyzes the force status of a prestressed anchor cable lattice beam in the tension stage. To simplify the calculation, there are some assumptions as follows:

(a) The dead weight of the lattice beam is not taken into account, and the effect of the beam top and foundation on the lattice beam is ignored.

(b) The effect of the prestressed anchor cable component force along the slope direction to the lattice beam is not taken into account.

(c) The effect of the torsion between the cross beam and the vertical beam at the lattice beam node is ignored.

(d) The absence of a friction force between the lattice beam and the rock and soil mass is assumed.

Under the above conditions, the mechanical model of the prestressed anchor cable lattice beam in the tension stage is shown in Figure 7.

\subsection{Analysis Results for the Internal Force of the Lattice Beam.} The internal forces of cross beam $\mathrm{H}_{2}$ and vertical beam $\mathrm{S}_{2}$ under the designed anchoring force are both calculated by the method described in this paper. In particular, the inertia moment of the lattice beam section is calculated by the traditional method and the transformed section method. The calculation results of the lattice beam moment are shown in Figure 8.

Figure 8 shows that the moments of the cross beam and the vertical beam are both symmetrically distributed. The larger positive moment appears at the point of the anchoring force, and the maximum negative moment appears at the midspan position of the beam. Both the maximum positive moments of the cross beam and vertical beam appear at the 
TABLE 1: The soil layer distribution on the slope.

\begin{tabular}{lccc}
\hline Soil layer number & Soil layer name & Thickness $(\mathrm{m})$ & Coefficient of subgrade reaction $\left(\mathrm{kN} / \mathrm{m}^{3}\right)$ \\
\hline (1) & Gravel soil & $0.5-3.0$ & $12000[18]$ \\
(2) & Strong weathering phyllite & $>15.0$ & - \\
\hline
\end{tabular}

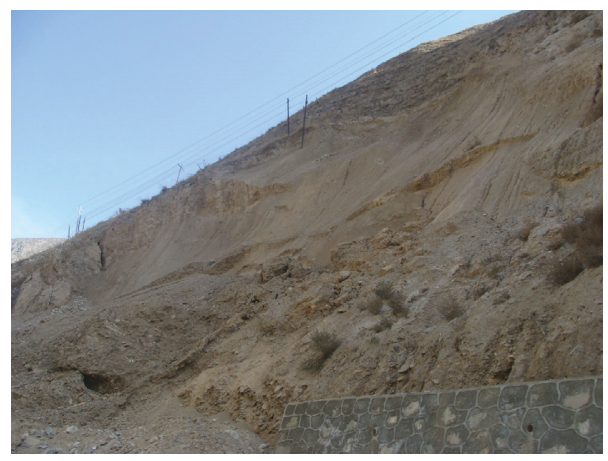

Figure 4: AB slope before reinforcement.

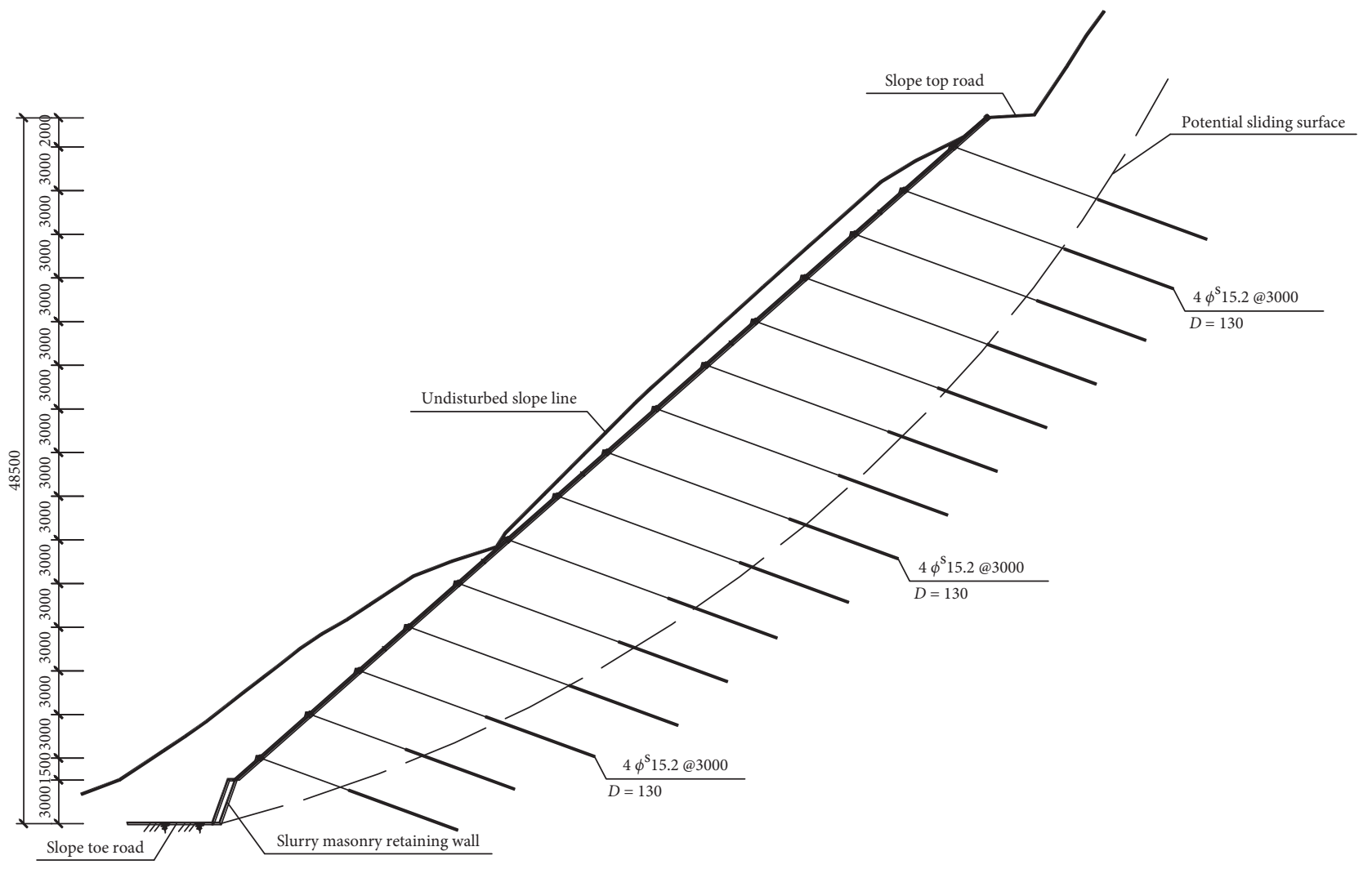

FIgURE 5: Typical section of the segment AB reinforcement design (mm).

exterior joint of the beam, and the situation is more obvious for the cross beam, which is related to the anchoring force distribution to the cross beam and vertical beam. In addition, the inertia moments of the beam section obtained by the traditional method and the transformed section method have an impact on the beam moment to the cross beam and vertical beam, and the impact on the vertical beam is greater than that on the cross beam. At the anchoring force action section of $\mathrm{S}_{2}$, the positive moment calculated by the transformed section method is $6.2 \%$ larger than that calculated by the traditional method. At the midspan position of $S_{2}$, the value of the negative moment calculated by the transformed section method is $10.1 \%$ larger than that calculated by the traditional method. 


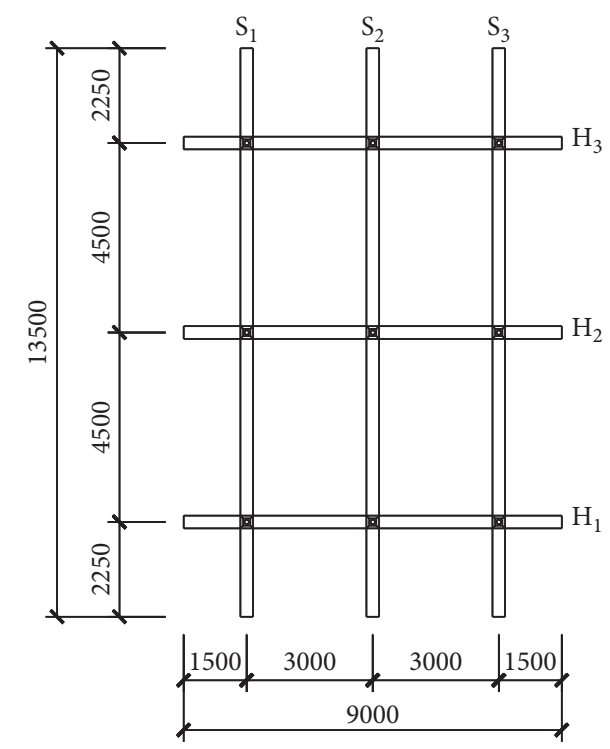

Figure 6: Schematic diagram of the lattice beam (mm).

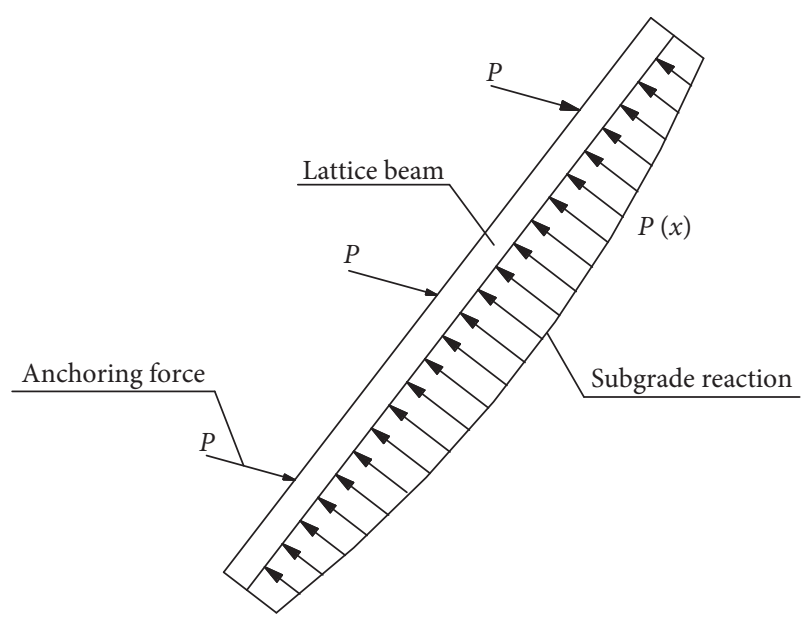

FIGURE 7: Mechanical model of the prestressed anchor cable lattice beam in the tension stage.

To study the effect of the anchoring force on the lattice beam moment, the vertical beam is regarded as the research object in this paper, and the theoretical moment of the key section is calculated by the traditional method and the transformed section method under the anchoring forces of $50 \mathrm{kN}, 100 \mathrm{kN}, 200 \mathrm{kN}, 300 \mathrm{kN}, 500 \mathrm{kN}$, and $800 \mathrm{kN}$. The calculation results are shown in Table 2.

According to Table 2, the greater the anchoring force is, the greater the moment of the lattice beam section is, and the two have the same proportional change phenomenon. Compared to the traditional method, the theoretical moment of the lattice beam key section can be increased by using the transformed section method, and the bending resistance of the lattice beam can be improved; then, the reinforcement ratio of the lattice beam section can be reduced under the same conditions, which can optimize the design of the lattice beam. The greater the anchoring force is, the greater the optimizing function is. In addition, the transformed section method considers the nonhomogeneous character of the lattice beam materials, which is more consistent with engineering practice.

\section{Field Test}

4.1. Design of the Test Scheme. Taking the typical section of segment $\mathrm{AB}$ as the object in this field test, as shown in Figure 5, four lattice beams of the typical section are selected to install sensors, which are named the first, second, third, and fourth from bottom to top. The sections of the midspan and the two ends in $\mathrm{H}_{2}$ and $\mathrm{S}_{2}$ are both selected to install sensors in each lattice beam, and two sensors are installed in each section, mounted symmetrically on the main reinforcement of the upper and lower sides in the section. Considering that the lattice beam has a certain symmetry under force, no sensor is installed on one side of $\mathrm{H}_{2}$, as shown in Figure 9. Five sections are selected in $\mathrm{H}_{2}$ of each lattice beam, and ten sensors are installed in total. Six sections are selected in $S_{2}$ of each lattice beam, and twelve sensors are installed in total. The sensor installation and design of the first lattice beam are different because of the impact of the construction factors in the later period.

In this test, the JMZX-416A intelligent string-type digital reinforcement stress meter is used to measure the stress. The stress meter is designed by vibrating string theory, and the vibration frequency of a steel string is converted into the stress value. With a sensitivity of $0.1 \mathrm{MPa}$, the sensor is equipped with an intelligent chip for automatic temperature correction, and the stress value can be directly read by the matched data acquisition system.

To reduce construction interference and ensure the authenticity and effectiveness of the measured data, the distance between the sensor at the end and the center of the adjacent node is $500 \mathrm{~mm}$. The stress meter is connected to the main reinforcement of the lattice beam by welding at both ends.

In addition, the anchor dynamometer is installed at the anchor head of the center node of each lattice beam to monitor the loss of anchor cable prestress at the tension stage and the change in the anchoring force at the working stage.

4.2. Calculation of the Measured Moment. In the field test, the moment of each section cannot be directly measured but can be back calculated by the measured stress and strain of the reinforcement [26]. In practical engineering, the lattice beam section is the double-reinforcement section. It is complicated to judge the tension side and the compression side of the beam section under the force action, and simultaneous compression or tension may occur on both sides. Therefore, the change in the neutral axis is an important factor that cannot be ignored.

Different from the previous methods, a method for calculating the measured moment of the diaphragm wall in foundation pit engineering is introduced to solve the measured moment of the lattice beam [27]. According to the method of material mechanics, the measured moment of the 


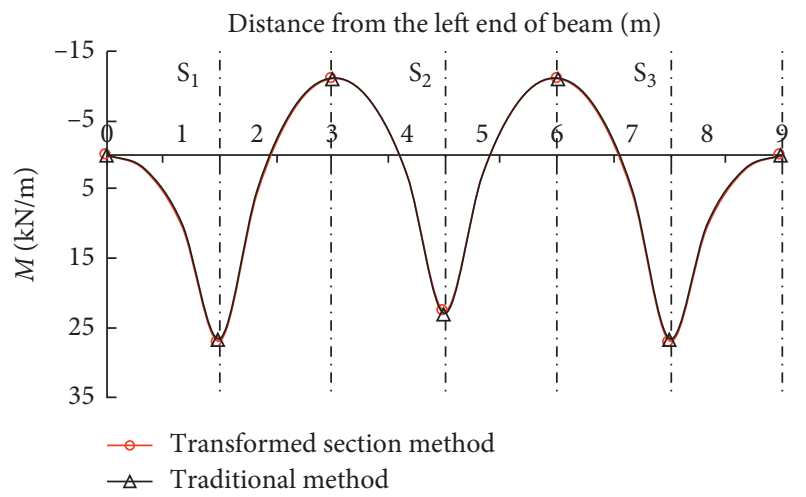

(a)

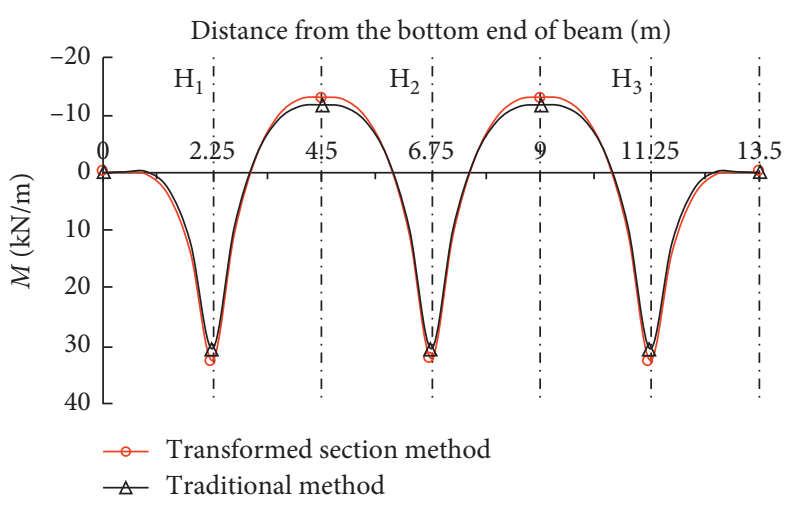

(b)

FIgURE 8: Comparison of the lattice beam. (a) Moment comparison of the cross beam $\mathrm{H}_{2}$. (b) Moment comparison of the vertical beam $\mathrm{S}_{2}$.

TABLE 2: The moments of the vertical beam obtained by two methods under different grades of anchoring force.

\begin{tabular}{|c|c|c|c|c|c|c|}
\hline \multirow{2}{*}{$\begin{array}{l}\text { Anchoring force } \\
(\mathrm{kN})\end{array}$} & \multicolumn{3}{|c|}{ Moment of the anchoring force action section $(\mathrm{kN} \cdot \mathrm{m})$} & \multicolumn{3}{|c|}{ Moment of the midspan section $(\mathrm{kN} \cdot \mathrm{m})$} \\
\hline & $\begin{array}{c}\text { Traditional } \\
\text { method }\end{array}$ & $\begin{array}{c}\text { Transformed section } \\
\text { method }\end{array}$ & Difference & $\begin{array}{l}\text { Traditional } \\
\text { method }\end{array}$ & $\begin{array}{c}\text { Transformed section } \\
\text { method }\end{array}$ & Difference \\
\hline 50 & 6.63 & 7.07 & 0.44 & -2.55 & -2.84 & -0.29 \\
\hline 100 & 13.26 & 14.14 & 0.88 & -5.11 & -5.69 & -0.58 \\
\hline 200 & 26.52 & 28.28 & 1.75 & -10.22 & -11.37 & -1.15 \\
\hline 300 & 39.79 & 42.42 & 2.63 & -15.33 & -17.06 & -1.73 \\
\hline 500 & 66.31 & 70.69 & 4.39 & -25.54 & -28.43 & -2.88 \\
\hline 800 & 106.10 & 113.11 & 7.02 & -40.87 & -45.48 & -4.61 \\
\hline
\end{tabular}

beam section is calculated by using the measured stress as follows:

$$
M=\frac{E_{\mathrm{c}}}{E_{\mathrm{s}}} \times \frac{I_{0}}{d}\left(\sigma_{1}-\sigma_{2}\right),
$$

where $M$ (in $\mathrm{kN} \cdot \mathrm{m}$ ) is the section moment to be measured, taking one running meter for the lattice beam, $E_{\mathrm{c}}$ and $E_{\mathrm{s}}$ are the elastic modulus of the concrete and reinforcement, respectively, $I_{0}$ is the inertia moment of the measured section, $d$ is the distance between a pair of reinforcement stress meters, and $\sigma_{1}$ and $\sigma_{2}$ are the stress values of the two reinforcement stress meters, which are positive when tension and negative when pressure.

Due to the nonuniformity of the lattice beam material, the inertia moment of the beam section is determined by the transformed section method, namely, $I_{0}=I_{\mathrm{c}}$. Meanwhile, the position $x_{\mathrm{c}}$ of the neutral axis is determined by the stress $\sigma_{\mathrm{s} 1}$ in the tension zone, and the stress $\sigma_{\mathrm{s} 2}$ in the pressure zone, and $\xi=\sigma_{\mathrm{s} 2} / \sigma_{\mathrm{s} 1} \cdot x_{\mathrm{c}}$ [27] is shown as follows:

$$
x_{c}=\frac{\xi}{1+\xi} h_{0}+\frac{\xi}{1+\xi} a^{\prime} \text {. }
$$

In the end, the measured moment of the lattice beam section is shown as follows:

$$
M=\frac{E_{\mathrm{c}}}{E_{\mathrm{s}}} \times \frac{I_{0}}{d}\left(\sigma_{\mathrm{s} 1}-\sigma_{\mathrm{s} 2}\right) .
$$

The parameter values needed for the measured moment in this test are shown in Table 3.

\section{Test Results and Comparative Analysis for the Internal Force of the Lattice Beam}

5.1. Comparative Analysis of the Measured Moment and Theoretical Moment. Four lattice beams are selected in this field test, and the measured reinforcement stress is used to calculate the measured moment of the lattice beam section, which is compared with the theoretical moment. The results of the first and second lattice beams are used for comparative analysis in this paper, and the comparative results are shown in Figures 10 and 11.

In this test, due to the complexity of the reinforcement distribution at the action point of the anchor cable, sensors are not installed on the section of the action point but on both sides of the section; hence, the measured moments on both sides of the section of the point are not connected in Figures 10 and 11. Shown as the measured moment, after the anchor cable is tensioned, the beam bottom of the node position in $\mathrm{H}_{2}$ and that in $\mathrm{S}_{2}$ are both in tension status, and the beam bottom of the midspan position in $\mathrm{H}_{2}$ and that in $\mathrm{S}_{2}$ are both in pressure status. The maximum positive moment appears at the action point of the anchor cable, and the maximum negative moment appears at the midspan position of the lattice beam.

The results show that the distribution trend of the measured moment is consistent with the theoretical results, and the measured values of the other points are smaller than the theoretical values except for several monitoring points. The reason is that the horizontal friction force between the 


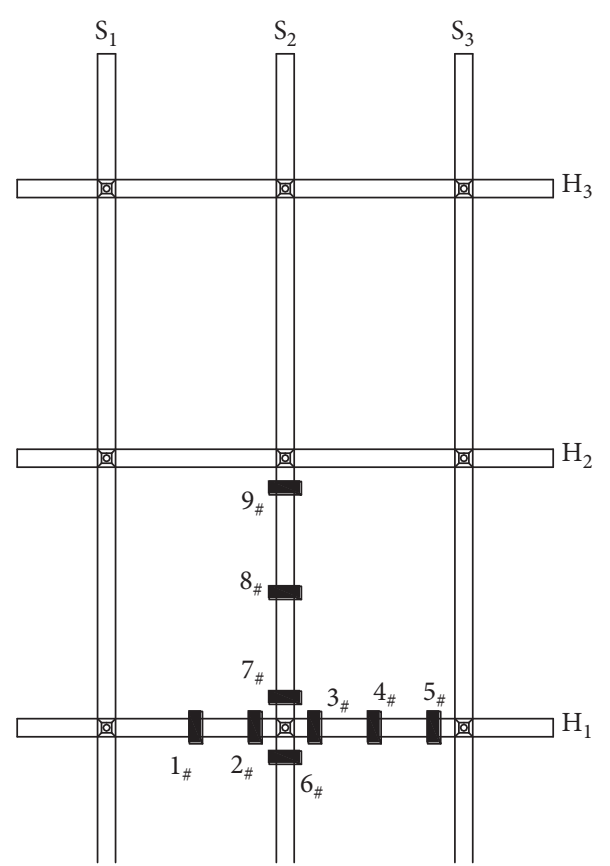

(a)

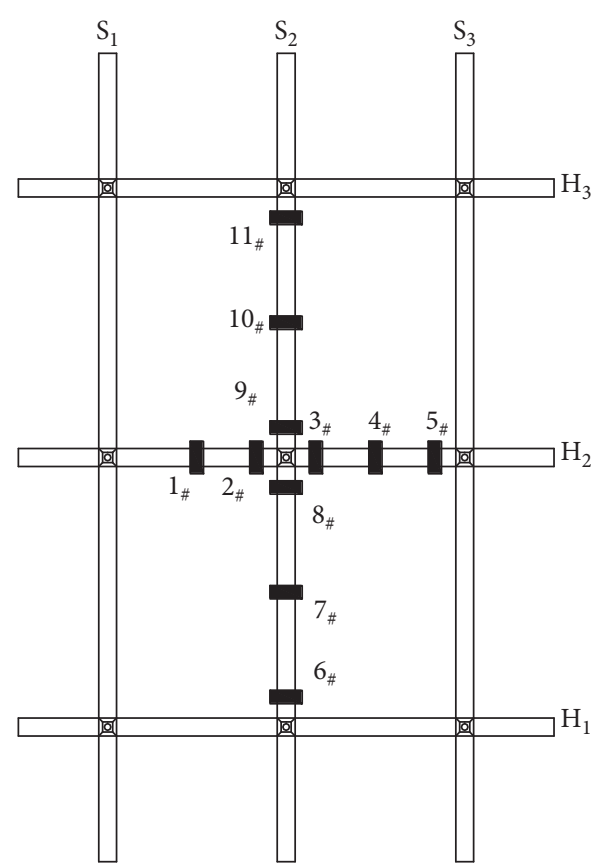

(b)

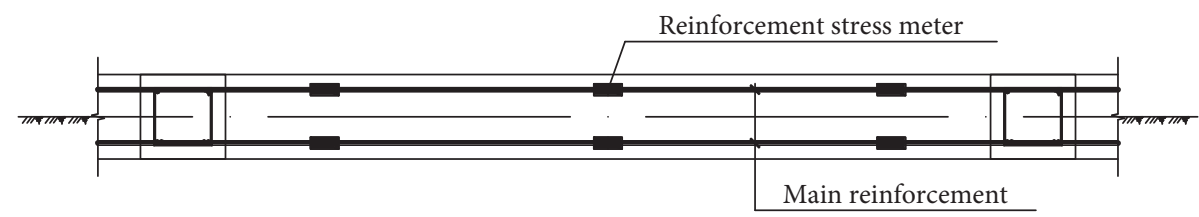

(c)

FIGURE 9: Schematic diagram of the sensor arrangement in a single beam. (a) Schematic diagram of the sensor arrangement in the first lattice beam. (b) Schematic diagram of the sensor arrangement in the second, third, and fourth lattice beams. (c) Schematic diagram of the sensor arrangement in a single beam.

TABLE 3: The parameters needed for the measured moment.

\begin{tabular}{cccccccccc}
\hline & $E_{\mathrm{s}}\left(\mathrm{N} / \mathrm{mm}^{2}\right)$ & $E_{\mathrm{c}}\left(\mathrm{N} / \mathrm{mm}^{2}\right)$ & $A_{\mathrm{s}}\left(\mathrm{mm}^{2}\right)$ & $A_{\mathrm{s}}^{\prime}\left(\mathrm{mm}^{2}\right)$ & $b(\mathrm{~mm})$ & $h(\mathrm{~mm})$ & $d(\mathrm{~mm})$ & $a(\mathrm{~mm})$ & $a^{\prime}(\mathrm{mm})$ \\
\hline Parameter value & 200000 & 28000 & 760 & 1520 & 300 & 300 & 200 & 50 & 50 \\
\hline
\end{tabular}

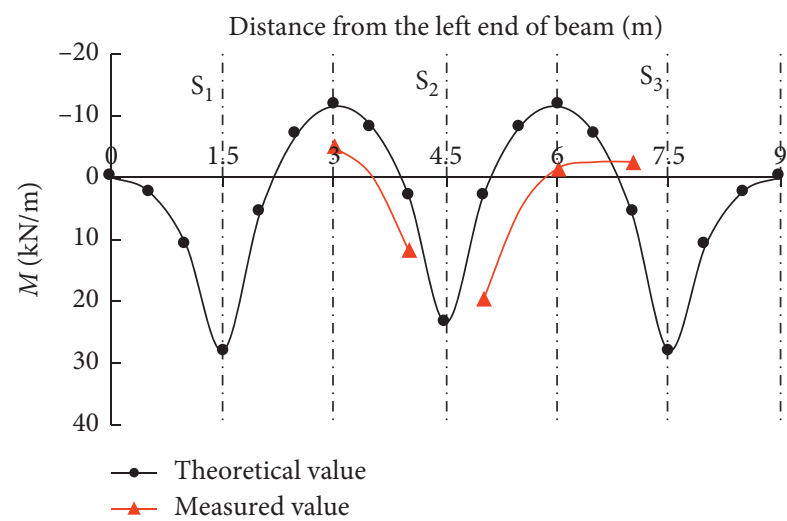

(a)

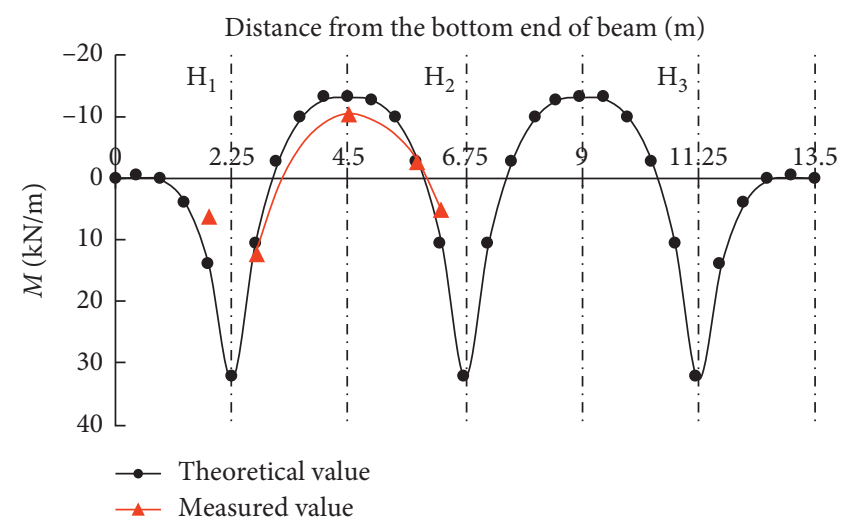

(b)

Figure 10: Comparison of the measured moment and the theoretical moment of the first lattice beam. (a) Comparison of the measured moment and the theoretical moment of $\mathrm{H}_{2}$. (b) Comparison of the measured moment and the theoretical moment of $\mathrm{S}_{2}$. 


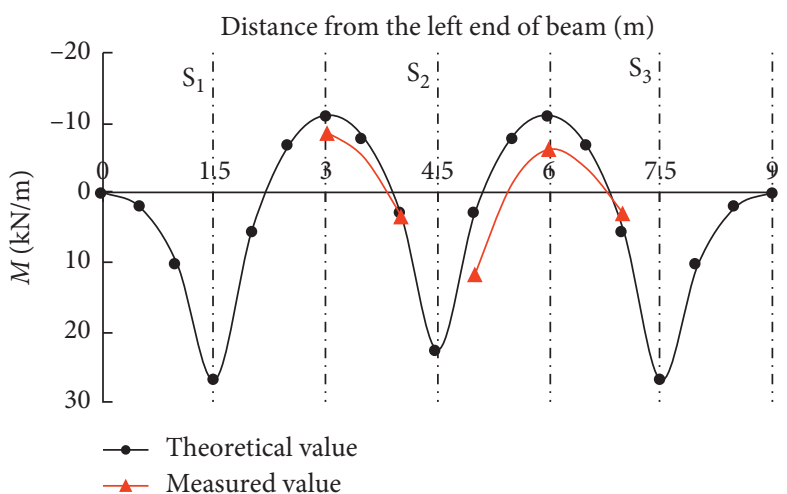

(a)

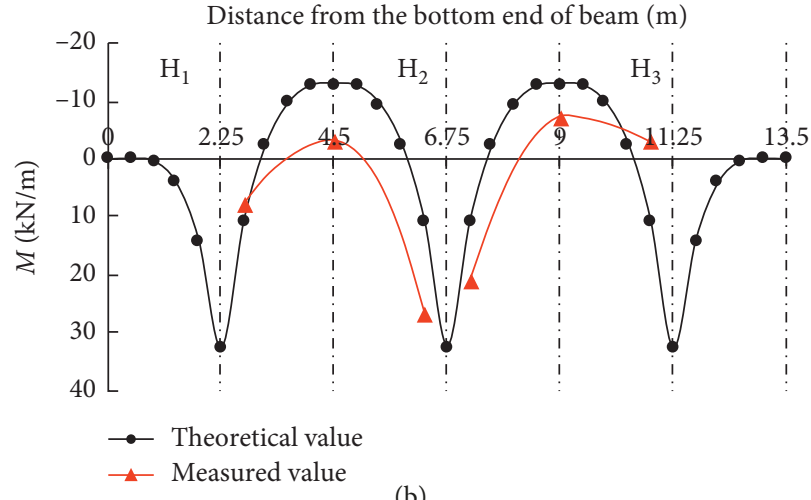

(b)

FIGURE 11: Comparison of the measured moment and the theoretical moment of the second lattice beam. (a) Comparison of the measured moment and the theoretical moment of $\mathrm{H}_{2}$. (b) Comparison of the measured moment and the theoretical moment of $\mathrm{S}_{2}$.

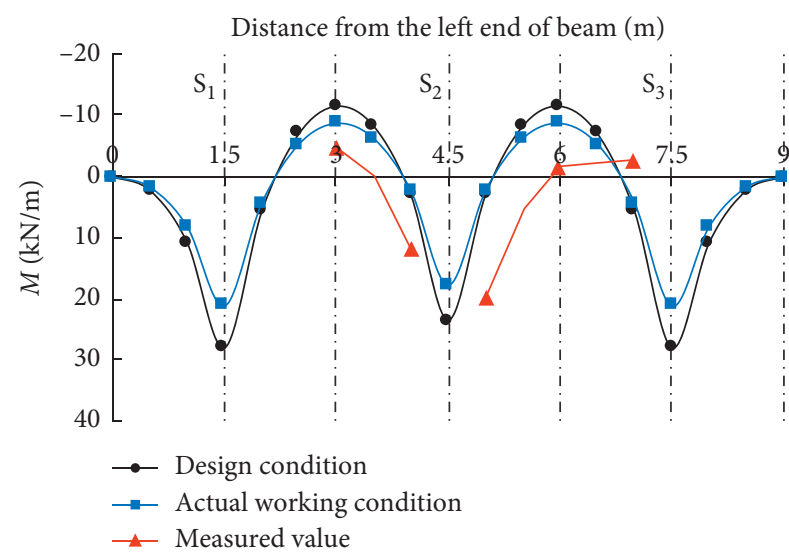

(a)

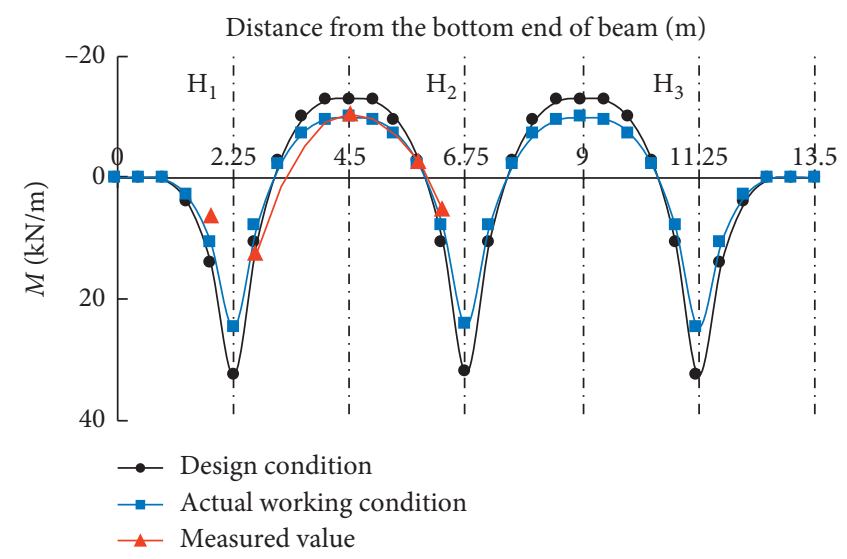

(b)

FIgURE 12: The moment comparison of the first lattice beam under three conditions. (a) The moment comparison of $\mathrm{H}_{2}$. (b) The moment comparison of $\mathrm{S}_{2}$.

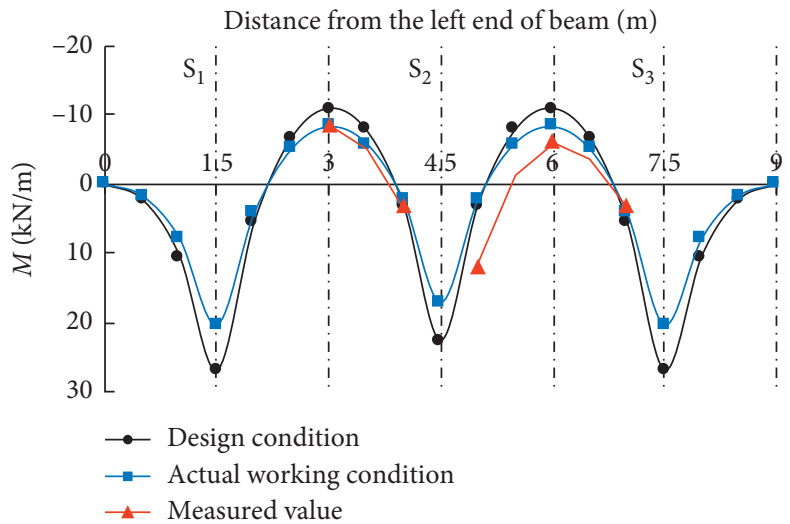

(a)

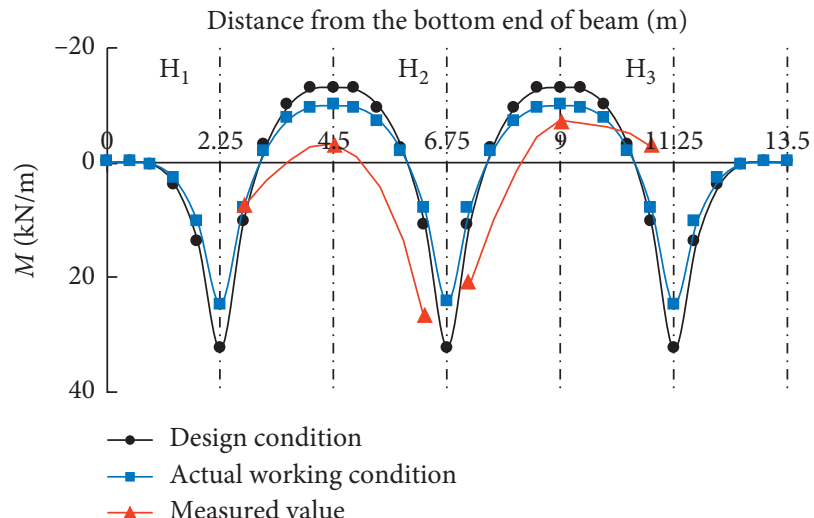

(b)

Figure 13: The moment comparison of the second lattice beam under three conditions. (a) The moment comparison of $\mathrm{H}_{2}$. (b) The moment comparison of $\mathrm{S}_{2}$.

rock and soil mass and the beam bottom is neglected in solving the theoretical moment, and the horizontal friction force has a large impact on the internal force and deformation of the beam. The loss of prestress is also an important reason for the smaller measured moment. In addition, due to the influence of construction factors, the 
installation sections of several sensors have a deviation from the design, which is the reason that the measured moments of these monitoring points are larger than the theoretical values.

5.2. Influence of the Measured Anchoring Force on the Internal Force of the Lattice Beam. Due to the impact of beam deformation, cement mortar strength, and anchorage, after the anchor cable is tensioned, the locking value of the anchoring force will be greatly reduced through an accelerated loss phase. The anchoring forces of some anchor cables are monitored in this test, and the measured data show that the average value of the measured anchoring force in the test area is $174 \mathrm{kN}$. The calculated results of the lattice beam moment under the actual working condition are obtained according to the theoretical method in this paper, and the calculated moment is compared with the theoretical moment under the design condition and the measured value in the test. The compared results are shown in Figures 12 and 13.

Compared with the results under the design condition, the theoretical moment at the key section of the cross beam and vertical beam are both significantly reduced under the actual working condition. The moment values are reduced by $24.35 \%$, which is the same as the loss rate of the anchoring force. The measured moment of the lattice beam is much closer to the calculated values under actual working conditions, and they are almost equal in Figure 12(b). The comparison results show that the anchoring force has an important effect on the internal force of the lattice beam.

\section{Conclusions}

In this paper, the internal force of a prestressed anchor cable lattice beam is studied by theoretical analysis and field testing, and the main conclusions are as follows:

(1) Based on the theory of the Winkler elastic foundation model, a mechanical model of the prestressed anchor cable lattice beam at the tension stage is established. An internal force calculation method of the "three horizontal and three vertical" lattice beam is given by introducing the transformed section method to solve the inertia moment of the area. Considering the nonhomogeneous materials of lattice beams, this method is more consistent with engineering practice. In addition, this method can increase the theoretical moment of the key section of the lattice beam; thus, the bending resistance of the lattice beam can be improved, and then, the reinforcement ratio of the lattice beam section can be reduced. The greater the anchoring force, the more obvious the lifting effect.

(2) Combined with the field test to study the internal force distribution trend of the lattice beam, this paper introduces a calculation method of the measured moment by using the measured stress. Considering the double-reinforcement section of the lattice beam and the change in position of the neutral axis under the actual force status, the results of this method are more accurate, which is more consistent with the actual working conditions.

(3) The distribution trend of the theoretical moment is consistent with the measured moment, which indicates that it is feasible to apply the calculation method of the measured moment described in this paper to solve the measured moment of the lattice beam. The measured moment is smaller than the theoretical moment, which indicates that the lattice beam is presently in the safety state.

(4) The anchorage force of the anchor cable has a significant effect on the internal force of the lattice beam. The greater the anchoring force, the greater the moment. In this paper, the measured anchoring force is substituted into the theoretical method, and the results show that the key section moment of the cross beam and vertical beam are both reduced by $24.35 \%$. Therefore, necessary measures should be taken to reduce the loss of the anchoring force and avoid the failure of lattice beams to ensure slope safety.

\section{Symbols}

$p(x)$ : Subgrade reaction

$q(x)$ : Load on the beam

$s: \quad$ Settlement of the foundation soil

$k$ : $\quad$ Coefficient of subgrade reaction

$b$ : Width of the beam

$\lambda$ : $\quad$ Flexibility eigenvalue of the beam

$h$ : Height of the beam

$a$ : Cover thickness of the steel in the tensile zone

$\omega$ : Deformation of the beam

$\omega_{1}(x)$ : Special solution of beam deformation

$E$ : $\quad$ Elastic modulus of the beam

I: $\quad$ Sectional inertia moment of the beam

$I_{\mathrm{c}}$ : Inertia moment of the transformed section to the neutral axis

$I_{0}$ : Inertia moment of the measured section in the test

$P_{0}$ : Concentrated force

$M_{0}$ : Concentrated couple

$x_{0}$ : Neutral axis height of the transformed section

$x_{\mathrm{c}}$ : $\quad$ Neutral axis height determined by the measured stress

$\bar{\omega}$ : $\quad$ Deformation of the infinite-length beam

$\bar{\omega}_{P_{0}}^{+}$: Deformation of the infinite-length beam on the right of $O$ under $P_{0}$

$\bar{\omega}_{P_{0}}^{-}$: Deformation of the infinite-length beam on the left of $O$ under $P_{0}$

$\bar{\omega}_{M_{0}}^{+}$: Deformation of the infinite-length beam on the right of $O$ under $M_{0}$

$\bar{\omega}_{M_{0}}^{-}$: Deformation of the infinite-length beam on the left of $O$ under $M_{0}$

$\bar{V}: \quad$ Shear force of the infinite-length beam section

$\bar{V}_{P_{0}}^{+}$: Shear force of the infinite-length beam on the right of $O$ under $P_{0}$

$\bar{V}_{P_{0}}^{-}$: Shear force of the infinite-length beam on the left of $\mathrm{O}$ under $P_{0}$ 
$\bar{V}_{M_{0}}^{+}$: Shear force of the infinite-length beam on the right of $O$ under $M_{0}$

$\bar{V}_{M_{0}}^{-}$: Shear force of the infinite-length beam on the left of $O$ under $M_{0}$

$F_{A}$ : Boundary condition force of the left end section of a finite-length beam

$F_{B}$ : $\quad$ Boundary condition force of the right end section of a finite-length beam

$\bar{M}_{P_{0}}^{+}$: Moment of the infinite-length beam on the right of $O$ under $P_{0}$

$\bar{M}_{P_{0}}^{-}$: Moment of the infinite-length beam on the left of $O$ under $P_{0}$

$\bar{M}_{M_{0}}^{+}$: Moment of the infinite-length beam on the right of $O$ under $M_{0}$

$\bar{M}_{M_{0}}^{-}$: Moment of the infinite-length beam on the left of $O$ under $M_{0}$

$M_{A}$ : Boundary condition couple of the left end section of a finite-length beam

$M_{B}$ : Boundary condition couple of the right end section of a finite-length beam

M: $\quad$ Section moment to be measured in the test.

\section{Data Availability}

The data used to support the findings of this study are available from the corresponding author upon request.

\section{Conflicts of Interest}

The authors declare no conflicts of interest.

\section{Acknowledgments}

This work was supported by Program for Changjiang Scholars and Innovative Research Team in University (no. IRT_17R51) and the National Natural Science Foundation of China (Project no. 51768040).

\section{References}

[1] F. Guzzetti, A. Carrara, M. Cardinali, and P. Reichenbach, "Landslide hazard evaluation: a review of current techniques and their application in a multi-scale study, Central Italy," Geomorphology, vol. 31, no. 1-4, pp. 181-216, 1999.

[2] R. Q. Huang, "Large-scale landslides and their sliding mechanisms in China since the 20th century," Chinese Journal of Rock Mechanics and Engineering, vol. 26, no. 3, pp. 433454, 2007.

[3] D. J. Peres and A. Cancelliere, "Modeling impacts of climate change on return period of landslide triggering," Journal of Hydrology, vol. 567, pp. 420-434, 2018.

[4] M. J. Froude and D. N. Petley, "Global fatal landslide occurrence from 2004 to 2016," Natural Hazards and Earth System Sciences, vol. 18, no. 8, pp. 2161-2181, 2018.

[5] U. Haque, P. F. da Silva, G. Devoli et al., "The human cost of global warming: deadly landslides and their triggers (19952014)," Science of the Total Environment, vol. 682, pp. 673684, 2019.

[6] M. Del Soldato, D. Di Martire, S. Bianchini et al., "Assessment of landslide-induced damage to structures: the agnone landslide case study (Southern Italy)," Bulletin of Engineering
Geology and the Environment, vol. 78, no. 4, pp. 2387-2408, 2019.

[7] Q. Lin and Y. Wang, "Spatial and temporal analysis of a fatal landslide inventory in China from 1950 to 2016," Landslides, vol. 15, no. 12, pp. 2357-2372, 2018.

[8] D. Petley, "Global patterns of loss of life from landslides," Geology, vol. 40, no. 10, pp. 927-930, 2012.

[9] S. Goel and N. R. Patra, "Effect of arching on active earth pressure for rigid retaining walls considering translation mode," International Journal of Geomechanics, vol. 8, no. 2, pp. 122-133, 2008.

[10] S. Ghareh, "Parametric assessment of soil-nailing retaining structures in cohesive and cohesionless soils," Measurement, vol. 73, pp. 341-351, 2015.

[11] G. Fan, J.-J. Zhang, S.-C. Qi, and J.-B. Wu, "Dynamic response of a slope reinforced by double-row anti-sliding piles and prestressed anchor cables," Journal of Mountain Science, vol. 16, no. 1, pp. 226-241, 2019.

[12] C. Sagaseta, J. M. Sánchez, and J. Cañizal, “A general analytical solution for the required anchor force in rock slopes with toppling failure," International Journal of Rock Mechanics and Mining Sciences, vol. 38, no. 3, pp. 421-435, 2001.

[13] C. Q. Huang, Y. P. Shen, J. H. Zhao, L. F. Mao, X. T. Yan, and Y. G. He, "Research on the reinforcement mechanism of prestressed anchor cable lattice beam and its site verification," Journal of Railway Engineering Society, vol. 32, no. 1, pp. 73-78, 2015.

[14] X. Y. Qin, D. P. Zhu, and Z. R. Shi, "Design and experimental investigation on prestressed anchor-cable lattice beam," Journal of Yangtze River Scientific Research Institute, vol. 25, no. 5, pp. 148-152, 2008.

[15] A. S. Gendy and A. F. Saleeb, "Effective modeling of beams with shear deformations on elastic foundation," Structural Engineering and Mechanics, vol. 8, no. 6, pp. 607-622, 1999.

[16] C. H. Liu and D. M. Wang, "Analysis of a cracked beamcolumn on an elastic foundation," International Journal of Computer Applications in Technology, vol. 13, no. 6, pp. 273-279, 2000.

[17] J.-H. Yin, "Comparative modeling study of reinforced beam on elastic foundation," Journal of Geotechnical and Geoenvironmental Engineering, vol. 126, no. 3, pp. 265-271, 2000.

[18] Y. Q. Long, Calculation of Elastic Foundation Beam, Public Education Press, Beijing, China, 1981.

[19] Y. Z. Xu and H. M. Tang, "Analysis of analytic solution of lattice frame anchor structure of landslide control," Geological Science and Technology Information, vol. 21, no. 3, pp. 89-93, 2002.

[20] Z. G. Zhou, Optimization Design and Safety Factor Calculation of the Slopes Reinforced by Pre-Stressed Anchors and Lattice Beams, Zhejiang University, Hangzhou, China, 2011.

[21] C. J. Song, P. D. Zhou, and S. G. Xiao, "Internal force calculation of beams with prestressed anchor-rope on foundation," Journal of Southwest Jiaotong University, vol. 36, no. 5, pp. 486-490, 2001.

[22] D. P. Zhu, E. C. Yan, and K. Song, "Research on interaction mechanism between lattice beam and slope rock mass and field test," Chinese Journal of Rock Mechanics and Engineering, vol. 28, no. S1, pp. 2947-2953, 2009.

[23] G. B. Liu and W. D. Wang, Excavation Engineering Manual, China Architecture and Building Press, Beijing, China, 2009.

[24] Z. H. Guo, Reinforced Concrete Theory, Tsinghua University Press, Beijing, China, 2013.

[25] Y. R. Zheng, Engineering Treatment of Slope and Landslide, China Communications Press, Beijing, China, 2010. 
[26] C. L. Chen, Y. P. Yin, Y. M. Men, and H. N. Liu, "Model test on fully grouted lattice beam anchorage," Chinese Journal of Rock Mechanics and Engineering, vol. 36, no. 4, pp. 881-889, 2017.

[27] G. B. Liu and Y. C. Wang, "Calculation of diaphragm wall moment by measured reinforcement stress," Underground Engineering and Tunnels, vol. 1, pp. 6-56, 2003. 


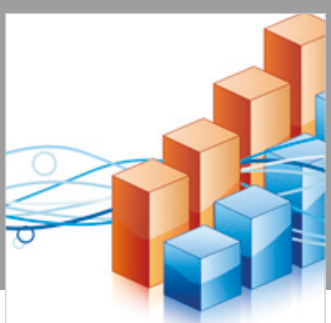

Advances in

Operations Research

\section{-n-m}
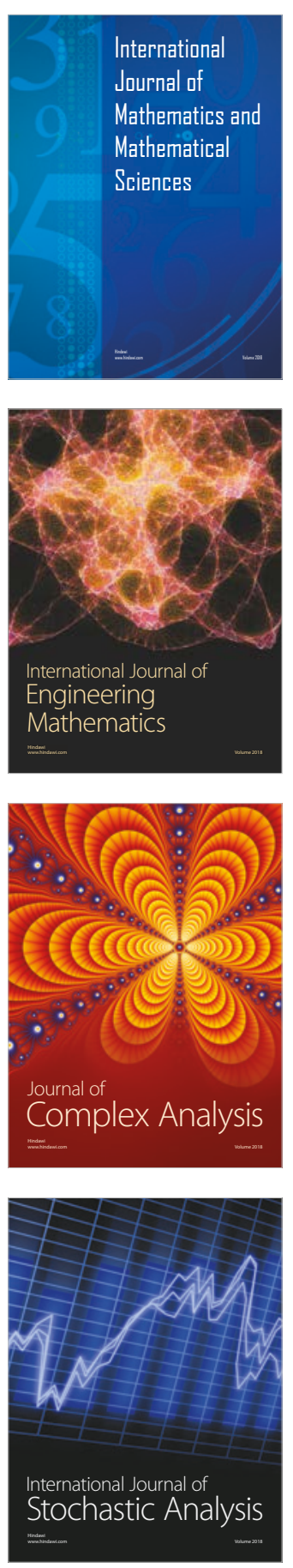
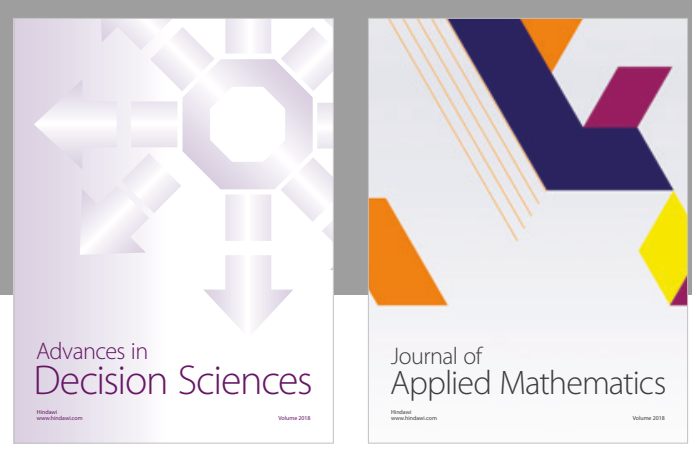

Journal of

Applied Mathematics
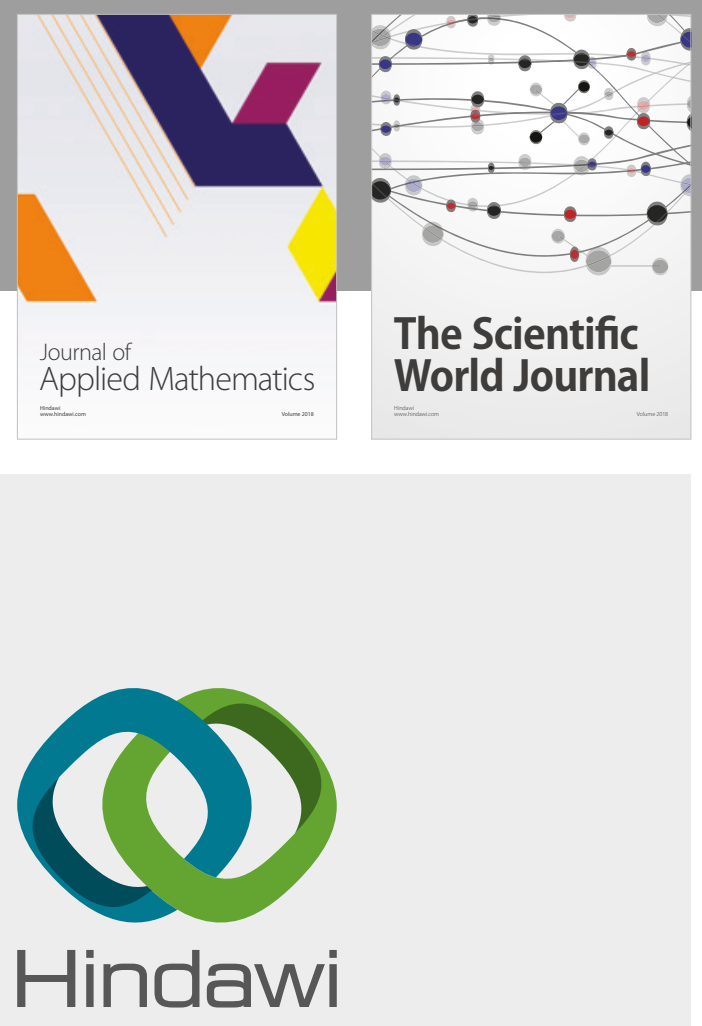

Submit your manuscripts at

www.hindawi.com

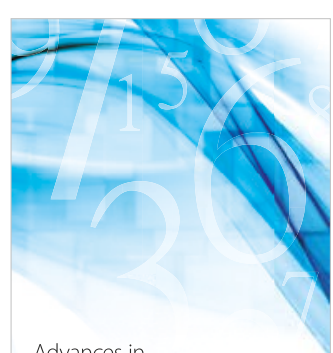

Advances in
Numerical Analysis
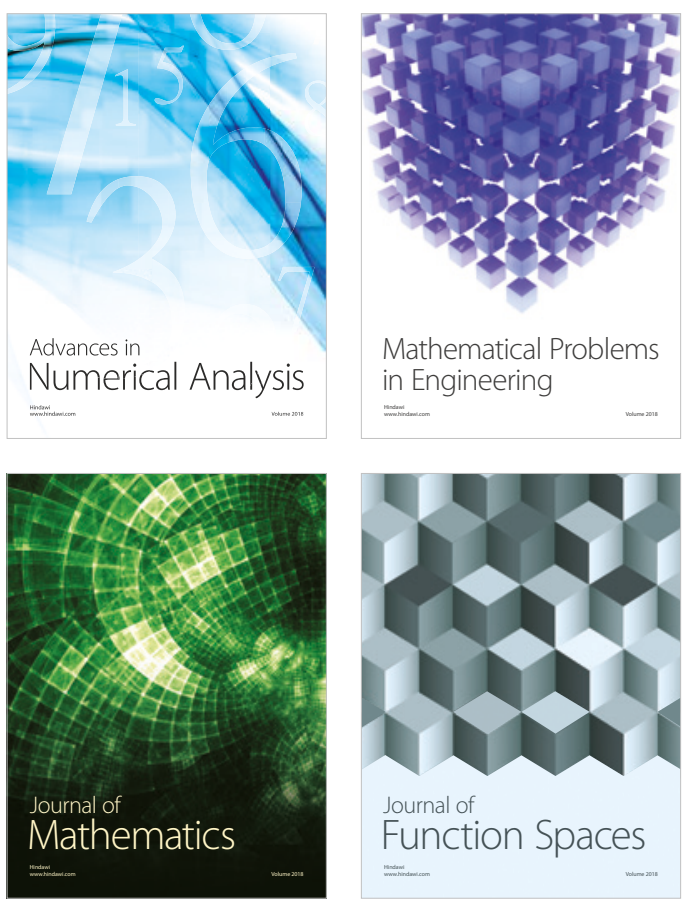

Mathematical Problems in Engineering

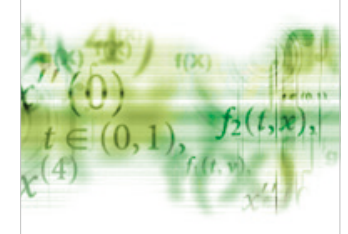

International Journal of

Differential Equations

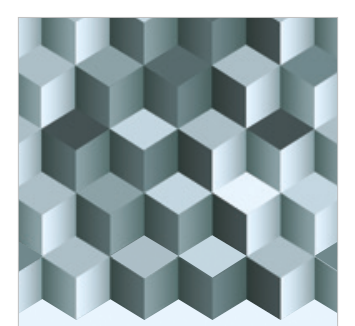

Journal of

Function Spaces

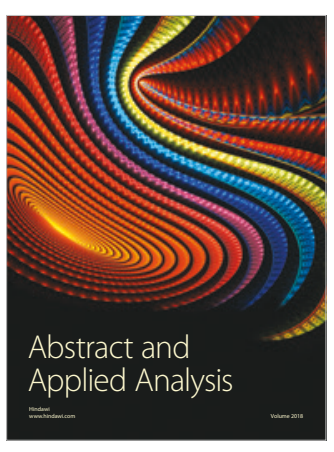

The Scientific

World Journal

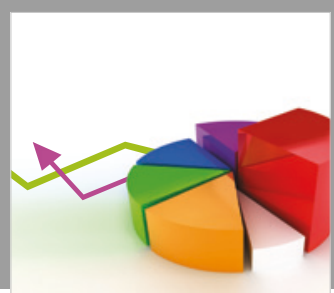

Journal of

Probability and Statistics
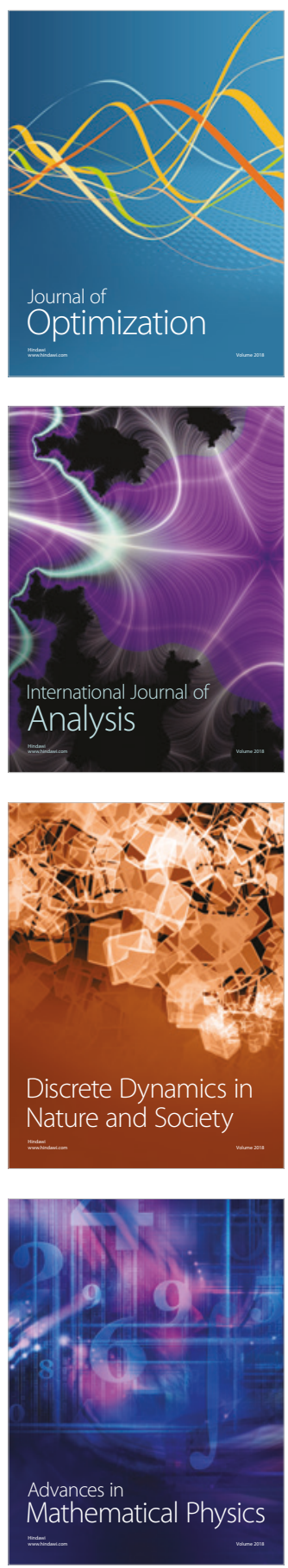